\title{
Experimental Study on Structural Form and Excavation Model of Urban Metro Cross Transfer Station with Super Large Cross Section and Shallow Excavation
}

\author{
Zhi Lin, ${ }^{1}$ Xiang Chen $₫$, ${ }^{1,2}$ Hongyun Yang $₫$, ${ }^{1}$ Chongguo Cheng, ${ }^{3}$ Huasong Wang, \\ Changjiang Yang, ${ }^{4}$ and Genqiao $\mathrm{Zhu}^{3}$ \\ ${ }^{1}$ State Key Laboratory of Mountain Bridge and Tunnel Engineering, College of Civil Engineering, Chongqing Jiaotong University, \\ Chongqing 400074, China \\ ${ }^{2}$ Chongqing Engineering Research Center of Disaster Prevention \& Control for Banks and Structures in \\ Three Gorges Reservoir Area, College of Civil Engineering, Chongqing Three Gorges University, Chongqing 404100, China \\ ${ }^{3}$ Transportation Research Institute Co., Ltd., China Merchants Group, Chongqing 400067, China \\ ${ }^{4}$ Chongqing Construction Engineering Municipal Traffic Engineering Co., Ltd., Chongqing 400045, China
}

Correspondence should be addressed to Xiang Chen; 20181035@sanxiau.edu.cn and Hongyun Yang; yanghy@cqu.edu.cn

Received 11 December 2019; Revised 15 February 2020; Accepted 17 February 2020; Published 11 May 2020

Academic Editor: Xueping Fan

Copyright $\odot 2020$ Zhi Lin et al. This is an open access article distributed under the Creative Commons Attribution License, which permits unrestricted use, distribution, and reproduction in any medium, provided the original work is properly cited.

The construction of urban underground cross-interchange transfer subway stations often encounters the difficulties of shallowburied, different surrounding rock, large spans and heights, congested road traffic, and surrounding buildings sensitive to the construction sequence. Therefore, there is a need for an underground project that controls the stability of underground space and ground subsidence. Based on the construction difficulties of a certain station (the maximum excavation area over $760 \mathrm{~m}^{2}$ ), this paper conducts a comprehensive selection design of the structure, construction mechanics response, and control technology of this type of interchange station structure and construction excavation. First of all, based on the design experience of large-scale underground transfer transportation engineering and taking full consideration of the stratum conditions, an "arch-wall" cross transfer structure method is proposed. The refined numerical analysis shows that the structure can fully utilize the stratum conditions to reduce the ground surface settlement. Then, in view of the stability of surrounding rock during the construction of a large section, based on the traditional large section excavation method, a construction method of "cross rock beam + heading method" was proposed. In order to verify the effect of the construction method, the three-dimensional detailed numerical model was used to simulate the construction conditions, and the mechanical response characteristics and displacement changes of surrounding rock under each excavation step are explored. Simultaneous interpreting with the traditional large section excavation method, the results show that the new method has advantages in controlling the stability of the surrounding rock. Meanwhile, in order to ensure the safe construction of the project, the self-developed multifunctional engineering test system for traffic tunnels is used to carry out a large-scale physical model experiment to simulate the entire process of the "arch-wall" cross transfer structure construction response characteristics. By analyzing the data of measuring points, the results show that the structure form and the excavation method cause the ground surface settlement, stress, and structural forces meet the requirements for safe construction. Finally, the station can be safely constructed under the new structure form and construction method. Therefore, the structure form and method proposed in this paper can be adapted to the large-scale underground structure under construction in complex environments. 


\section{Introduction}

Traffic congestion in large cities has become the norm. Transferring ground roads to underground projects is one of the effective ways to resolve the contradiction between the rapid increase in vehicle ownership and the difficult land expansion $[1,2]$. Therefore, the development of rail transit and urban underground ring roads has become the primary choice for major cities to solve and improve urban transportation, to systematically solve the problem of urban spatial layout and the configuration of transportation network construction, and to fundamentally improve the current urban traffic conditions [3, 4]. With the comprehensive development of underground space and the continuous expansion of underground engineering, the problem of tunnel crossing caused by multiline transfers has gradually become the norm [5]. In addition, the form of cross tunnels is becoming more and more complicated. Cross tunnels have evolved from the cross of single holes to the complex cross of porous holes [6-8]. In general, a cross tunnel is a type of close-spaced engineering. The mechanical characteristics of the surrounding rock and supporting structure of a tunnel are closely related to its structural characteristics and crossline shape $[9,10]$.

Since this type of underground engineering or rock underground engineering is more sensitive to excavation construction, the overall engineering is complex and the construction is difficult; the main difficulties are as follows: (1) rail transit is generally shallow-buried, and there are complex surrounding environments such as buildings (structures) and municipal pipe networks. When the new and old structures are relatively close, the excavation of the tunnel will cause the rock and soil around the existing structure. Disturbances will cause stress redistribution of surrounding rocks, which may easily cause safety accidents such as the decline or even destruction of the bearing capacity of structures, ground subsidence, and pipe network fractures [11-13]. (2) Due to the complex relationship between rail transit transfers and rail transit sections, the mutual influence is large, which makes the design and construction difficult $[14,15]$. Therefore, the tunnel excavation technology must be researched in depth to solve the problems existing in the excavation of shallow-buried tunnels with very large cross sections to ensure the safe construction of urban rail transit [16, 17]. (3) From the perspective of the stability of surrounding rock, due to the mutual effect of the large-span tunnel and due to the size effect of the rock structure, the magnification effect of the surrounding rock defects the influence circle and the sensitive effect of the construction sequence after the excavation of the rock mass. The traditional empirical method and engineering analogy method can no longer meet the requirements of stability of surrounding rocks and supporting structures [18].

At present, the construction of large-scale underground projects is mainly concentrated in underground powerhouse of a hydropower station, military ammunition depots, large granaries, metro stations, and 4-lane highway tunnels. Such projects are generally deep-buried tunnels $[15,19,20]$. The tunnel engineering cross section uses a variety of cross types $[21,22]$ : for example, the Russian cross tunnel uses a doublehole double-layer tunnel type; the Italian-Swiss highway in Milan's two-lane cross tunnel-type runs from horizontal to parallel and cross to vertical parallel; the newly constructed east-west Tozai subway tunnel in Japan uses a line pattern similar to the four-hole twist to intersect the existing Keishin line; the first phase of the Shenzhen subway project, from the Guomao Station to the Old Street Station [23] uses left and right overlapping structure of the line; Shanghai Metro Line 2 adopts the way of crossing up and down when crossing with Line 1 [24]. The vertical clear distance between the top and bottom is about $1 \mathrm{~m}$. The above projects cover the main types of cross structures for proximity projects and more difficult studies such as shallow-buried three-dimensional cross tunnels with very large cross sections.

Therefore, in this paper, a super-large section of a subway station in Chongqing city with a shallow-buried tunnel is used as the engineering background. The optimization of the three-dimensional cross structure, the deformation characteristics of surrounding rocks, the construction method of large sections, and the stress and deformation laws of surrounding rocks during the excavation are studied. The research results will accumulate experience for the design and construction of super-largespan shallow-buried urban tunnels and provide reference and technical experience for the design and construction of similar projects in the future.

\section{Structural Optimization of Large-Scale Three-Dimensional Interchange Stations in Rail Transit}

2.1. Analysis of Cross Structure Forms. In this paper, we study an underground transfer-station intersection with a large excavation space. The research station is a cross exchange hub for Light Rail Transit Line 3 and Subway Line 6, and it belongs to a shallow-buried underground structure with a large cross section. The ground structures above the station are complex, including Hefu Hotel and Shengtai Automobile City on the east side, North Bus Station on the west side, bus junction station, Ideal Building, and Donghe Yindu Business District. The clearance areas of sections A and $\mathrm{B}$ are $580.21 \mathrm{~m}^{2}$ (the maximum excavation area over $760 \mathrm{~m}^{2}$ ) and $383.65 \mathrm{~m}^{2}$, respectively. The traditional crossover design for a large section is a vault crossing (Figure 1(a)). With the two vaults at the same elevation, the large excavation span and area can lead to many problems, such as a complex overall tunnel structure, uneven distribution of arch structure stress, surrounding rock during tunnel construction that is prone to landslides, difficulty in underground engineering construction control, and additional engineering project risks. To solve the above problems, this paper proposes an arch-wall structure in the intersection, increasing the arch elevation of the large section and forming a small-clearance tunnel through the large-clearance tunnel (Figure 1). 


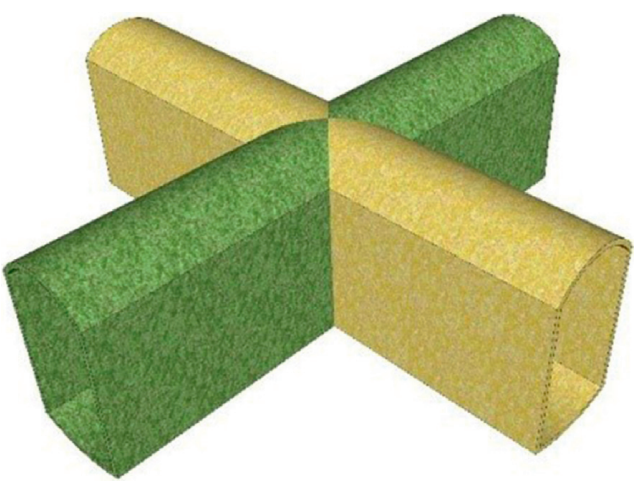

(a)

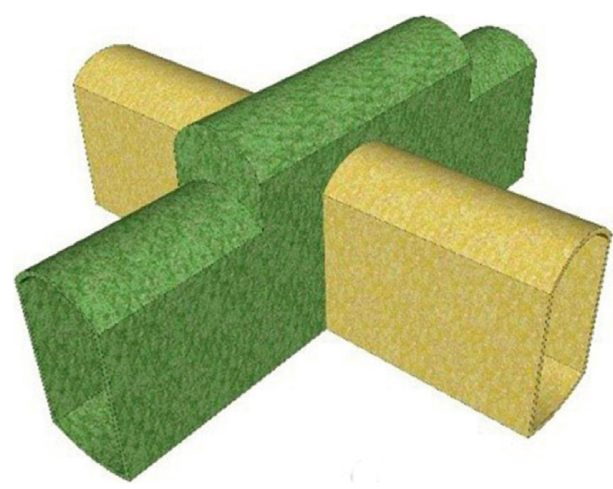

(b)

FIGURE 1: Structure schematic of underground transfer-station intersection: (a) arch-arch; (b) arch-wall.

2.2. Comparative Analysis of Three-Dimensional Cross Schemes. Three-dimensional finite element numerical simulation is carried out to analyze the structural stress and surrounding rock-response characteristics of an arch-arch and arch-wall.

2.2.1. Determination of Computational Area. Considering the impact of underground engineering excavation, the horizontal size of the finite element computational model is set at 1.5-7.5 times the tunnel lateral span. At the bottom of the tunnel, 3 times the excavation height of the station is considered, and at the top of the tunnel, the actual buried depth of the station tunnel is considered. The size of the actual numerical calculation model is $100 \mathrm{~m} \times 90 \mathrm{~m} \times 104 \mathrm{~m}$.

\subsubsection{Setting of Boundary Conditions for Finite Element} Numerical Model Analysis. The upper part of the model is a free boundary; the other directions are considered as normal constraints. The initial stress is calculated only in terms of the gravity stress field due to shallow construction, and the material mechanical parameters of the model are shown in Table 1.

Twenty points on the ground surface of the tunnel are set as monitoring points, and the surface subsidence value is processed. The changing tendency of surface monitoring point subsidence is shown in Figure 2. The results show that the maximum settlement subsidence caused by excavation of the tunnel is at the top of the tunnel axis, the maximum settlement of the arch-arch structure is $14.7 \mathrm{~mm}$, and the maximum settlement of the arch-wall structure is $12.0 \mathrm{~mm}$. The surface sedimentation value decreased by $19.2 \%$. As the arch-wall cross structure raises the tunnel vault, it has greater effect on both sides of the surface along the tunnel axis than the arch-arch cross structure.

The selection of the construction plan should consider the minimum ground settlement control and the reasonable stress on the tunnel structure. From the above comparative analysis, it can be known that it is reasonable and feasible to choose the "arch-wall" crossover scheme as a large-scale rail transit crossover station structure.
TABle 1: Parameters of the material.

\begin{tabular}{|c|c|c|c|c|c|c|}
\hline No. & Materials & $\begin{array}{c}\rho \\
\left(\mathrm{kg} \cdot \mathrm{m}^{-3}\right)\end{array}$ & $\begin{array}{c}E \\
(\mathrm{GPa})\end{array}$ & $\mu$ & $\begin{array}{c}c \\
(\mathrm{MPa})\end{array}$ & $\theta\left(^{\circ}\right)$ \\
\hline 1 & $\begin{array}{l}\text { Surrounding } \\
\text { rock }\end{array}$ & 2,500 & 2.45 & 0.34 & 1.2 & 34.78 \\
\hline 2 & Anchorage & 2,500 & 2.45 & 0.30 & 1.35 & 34.78 \\
\hline 3 & Primary support & 2,200 & 23 & 0.32 & - & - \\
\hline 4 & Second lining & 2,200 & 23 & 0.22 & - & - \\
\hline
\end{tabular}

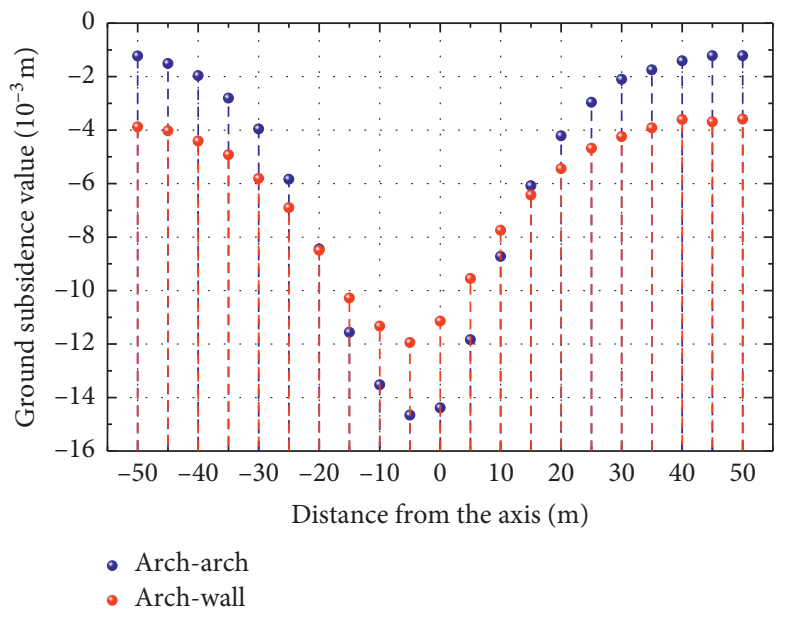

Figure 2: Comparison of two types of structural surface displacement.

\section{Shallow-Buried and Concealed Excavation Construction Technology for Large Section of Large Underground Station}

From the standpoint of rock-mass mechanics, tunnel construction will cause strain and stress responses in surrounding rock, and the rock stress will redistribute in the process of cavern excavation and support work. Obviously, the tunnel excavation and support work not only affect the rock stress-strain but also construction safety and underground structure stability. Based on shallow, large section underground structures, and similar engineering experiences, we introduce a new excavation approach called the 
cross rock beam + heading method, based on the double-side pilot heading excavation method, for a certain transfer station. This paper also proposes a proper construction plan by analyzing the ground surface settlement and the stress conditions for the above methods.

\subsection{Excavation Method for Super-Large Section}

3.1.1. Double-Side-Wall Heading Excavation Method. The tunnel cross section is divided into three parts for the double-side-wall heading excavation method (Figure 3(a)). Both sides are headings and the central part is core soil, which can effectively control the unwinding of the surrounding rock and ensure the tunnel-face stability. This kind of benching method is beneficial to the stability of a superlarge section tunnel, but the high lane section will increase the construction excavation difficulties, and the model board trolley is higher, which is not conducive to design and for operation of large machines. Therefore, it fails to ensure a predictable construction period and efficient excavation. The numbers in the figure represent the processes of excavation, temporary support and demolition, and permanent support.

From the actual situation of the large section, the main advantages of the tunnel excavation of the station tunnel with the double-side-wall heading excavation method are as follows:

(1) When the left and right guide pits are used to divide the tunnel section into multiple sections by steps, the span of the excavation face can be greatly reduced, and the intermediate core soil effectively controls the relaxation of the surrounding rock of the tunnel, which better controls ground settlement deformation, effectively guaranteeing the stability of the tunnel.

(2) The plan also fully considers the detailed structural design requirements of the underground station structure and reserves sufficient construction conditions and space for the structures it needs to lay out.

However, the following problems in the construction of this method cannot be ignored:

(1) According to the actual situation of excavation, the overall excavation height is relatively large, reaching nearly $30 \mathrm{~m}$, which is not good for controlling the safety of construction machinery;

(2) After excavation of the tunnel section, the secondary lining support of the surrounding rock cannot be closed in time, which is disadvantageous for the stress control of the surrounding rock and the supporting structure;

(3) In order to integrate the secondary lining support of the tunnel arch and the side wall, a formwork trolley with a height of $32 \mathrm{~m}$ and a width of $23 \mathrm{~m}$ needs to be arranged. Such a large formwork trolley has no precedent in China at present, and the overall difficulty is relatively large. The cost is relatively high.
3.1.2. Cross Rock Beam + Heading Method. The cross rock beam + heading method (Figure $3(\mathrm{~b})$ ) is based on the double-side-wall heading excavation method for the high excavation section. This plan adopts the benching method. It starts excavating a pilot tunnel from the four corners, and then, it removes the rock beam after the initial support and invert arch lining work, which can significantly reduce the headroom of the tunnel excavation section. The numbers in the figure represent the processes of excavation, temporary support and demolition, and permanent support.

The new method makes full use of the advantages of the double-side-wall heading excavation. By retaining horizontal rock beams in the middle of the tunnel excavation section, the two sides of the guide pit are divided into four relatively small sections and excavated separately. The excavated rock mass forms a "cross" rock beam. The main advantages of this method are as follows:

(1) Make full use of the excavation section of the station tunnel section. By increasing the excavation working face, not only can the tunnel surrounding rock deformation be effectively controlled, but the construction excavation speed is also accelerated;

(2) By making full use of the role of the "cross" rock beam reserved in the middle, the strength of the horizontal support is enhanced, and the overall stability of the surrounding rock of the tunnel is effectively guaranteed;

(3) Due to the arrangement of the middle rock beam, the backfill of the lower guide tunnel can reduce the construction height of the secondary lining of the underground station and effectively solve the layout problem of the super-large section formwork trolley.

3.2. Numerical Simulation Analysis. In order to facilitate the calculation, the actual model needs to be reasonably simplified. In actual engineering, the role of the surrounding rock bolt support and system bolts is to enhance the integrity and bearing capacity of the surrounding rock. It can be achieved by adjusting the surrounding rock parameters in the calculation. Rod support and system anchors can no longer be considered separately. In this paper, the principle of equivalence is used to simplify the role of anchor support and system anchors in strengthening surrounding rocks. The theoretical basis is to consider the role of temporary support by increasing the cohesion and internal friction angle of the surrounding rock, but because the internal friction angle changes relatively little, only considering the increase in cohesion, the cohesion can be calculated by the following formula [25]:

$$
C=C_{0}\left(1+\frac{\eta \tau s_{\mathrm{m}}}{9.8 a b} \times 10^{4}\right)
$$

where $C$ is the cohesion of the surrounding rock after considering the support of the anchor $\operatorname{rod}(\mathrm{MPa}) ; C_{0}$ is the cohesion of the actual rock mass $(\mathrm{MPa}) ; \tau$ is the shear strength of the anchor bar (MPa); $s_{\mathrm{m}}$ is the cross-sectional area of the anchor reinforcement $\left(\mathrm{m}^{2}\right) ; a$ and $b$ are the 


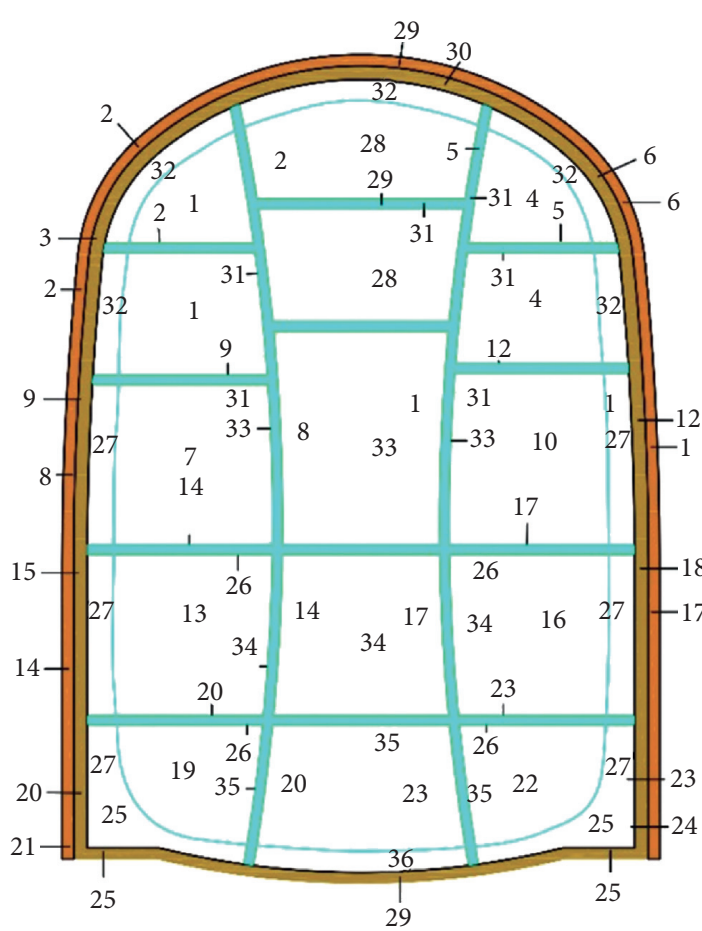

(a)

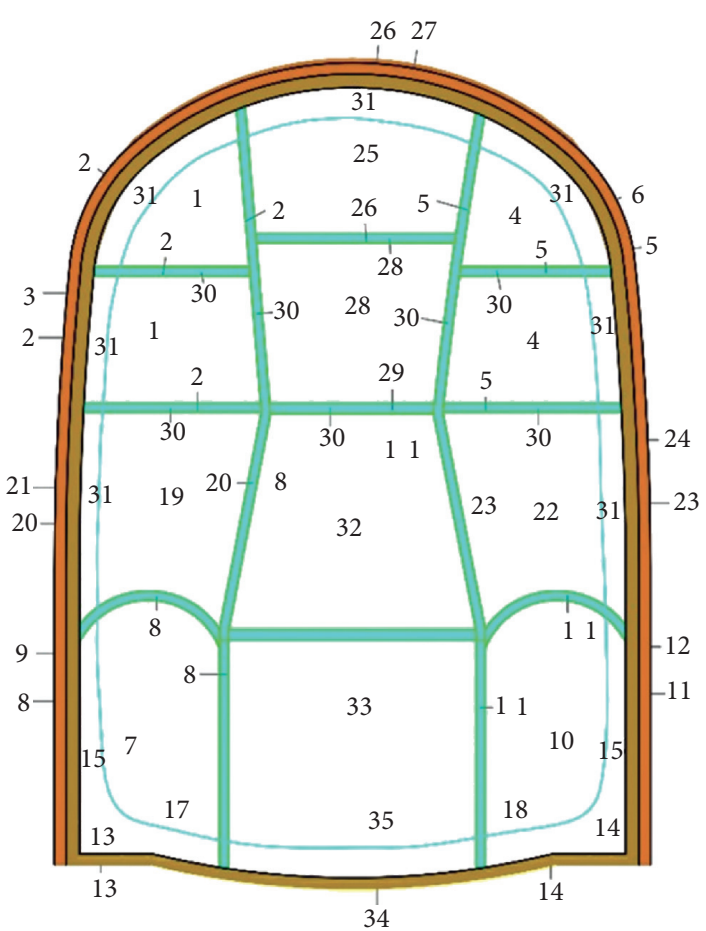

(b)

Figure 3: Excavation process of super-large section tunnel: (a) process of the double-side-wall heading excavation method; (b) process of the cross rock beam + heading method.

longitudinal and horizontal distances $(\mathrm{m})$ of the anchor, respectively; $\eta$ is the empirical coefficient.

The relevant parameters of the other materials in the calculation model are based on the detailed survey report of the station. The main material calculation parameters are shown in Table 2.

3.2.1. Displacement Analysis. To analyze settlement deformation of the large section underground station using different construction procedures, we selected 13 monitoring points in the middle of the cross section above the surface of the underground station (Figure 4). The results show that the maximum ground settlements caused by the double-side-wall heading excavation method and the cross rock beam + heading method are $11.98 \mathrm{~mm}$ and $9.81 \mathrm{~mm}$, respectively. The range of surface settlement caused by excavation is about $60 \mathrm{~m}$ in the two sides of the station axis and five times the span of the transfer station. Similarly, in order to analyze the displacement of the tunnel periphery caused by different excavation methods and considering the symmetry, three positions of the left wall foot, left flank wall, and left arch foot on one side were selected as monitoring points. The analysis results are shown in Table 3.

By analyzing the cavity displacement caused by two excavation methods, we found that the vault subsidence deformation caused by the cross rock beam + heading method is smaller. Generally, the maximum level convergence of the surrounding rock appears between the tunnel arch foot and wall waist by adopting the two excavation methods, but the horizontal displacement convergence of the surrounding rock caused by the cross rock beam + heading method is smaller due to the support of the middle rock beam.

3.2.2. Stability Analysis of Surrounding Rock. According to the contrast analysis of Figures 5 and 6, neither method caused the surrounding rock to form the failure surface; it is seen that the surrounding rock of the tunnel is stable. The maximum plastic strain is $1.43 \times 10^{-3}$ with the double-sidewall heading construction method, and it is $1.17 \times 10^{-3}$ with the divided heading construction method. Surrounding rock is more stable with the divided heading construction method because its plastic zone is smaller than that of the doubleside-wall heading construction method.

3.2.3. Stress Analysis of Surrounding Rock. We estimate the plastic state and monitor the damages of the surrounding rock by the strength coefficient of Gauss points in Mohr-Coulomb:

$$
\text { S.M.F }=\frac{\sigma_{1}-\sigma_{3}}{2 c \cdot \cos \varphi+\left|\sigma_{1}+\sigma_{3}\right| \sin \varphi} .
$$

If S.M.F $\geq 1$, then the gauss point has entered the plastic state.

We can summarize the above two methods in Table 4, which presents the main stress value in key nodes of the surrounding rock. Figure 7 shows the gauss effective 
TABle 2: Parameters of the material.

\begin{tabular}{|c|c|c|c|c|c|c|}
\hline No. & Materials & $\begin{array}{c}\rho \\
\left(\mathrm{kg} \cdot \mathrm{m}^{-3}\right)\end{array}$ & $\begin{array}{c}E \\
(\mathrm{GPa})\end{array}$ & $\mu$ & $\begin{array}{c}c \\
(\mathrm{MPa})\end{array}$ & $\theta\left(^{\circ}\right)$ \\
\hline 1 & $\begin{array}{l}\text { Surrounding } \\
\text { rock }\end{array}$ & 2,500 & 2.45 & 0.34 & 1.2 & 34.78 \\
\hline 2 & Anchorage zone & 2,500 & 2.45 & 0.30 & 1.35 & 34.78 \\
\hline 3 & Primary support & 2,200 & 23 & 0.32 & - & - \\
\hline 4 & $\begin{array}{c}\text { Temporary } \\
\text { support }\end{array}$ & 2,200 & 23 & 0.22 & - & - \\
\hline 5 & Bracing beams & 7,850 & 210 & 0.22 & - & - \\
\hline
\end{tabular}

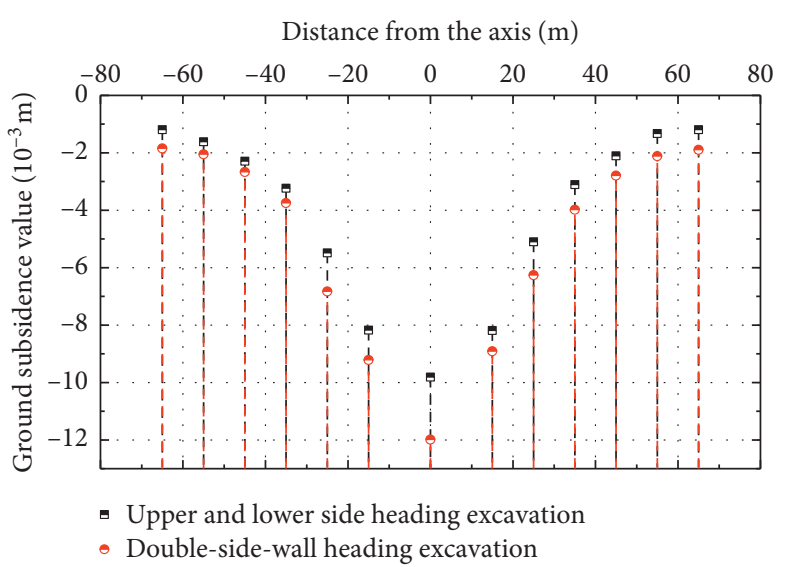

FIGURE 4: Curve of surface subsidence deformation.

strength coefficient calculated by formula (1). This is higher for the double-side-wall method than for the cross rock beam + heading method. This means that the plastic deformation development of the double-side-wall method is more rapid than that of the cross rock beam + heading method, and the surrounding rock of the double-side-wall method is more stable. In addition to the tunnel vault location, the principal stress value of the surrounding rock with the cross rock beam + heading method is smaller than that of the double-wall pilottunnel method.

\subsection{The Production of Three-Dimensional Geological Model}

3.3.1. Experimental Program. In this paper, we have conducted model tests, based on engineering design and excavation, of the mechanical characteristics and deformation law of a shallow-buried large section underground tunnel. To simulate the actual excavation, cross structure, and surrounding rock deformation, we perform related research on the excavation of a cross section beside a shallow-buried large section tunnel. The test specimen measures $3.2 \mathrm{~m} \times 4.0 \mathrm{~m} \times 2.4 \mathrm{~m}$, and the maximum value of the simulated tunnel span is $0.8 \mathrm{~m}$. The basic bearing components are a frame type of steel structure (Figure 8). We installed a load cylinder, which can transfer pressure evenly to the test specimen through a force plate around the steel structure. The pressure around the specimen can be adjusted by a hydraulic system, and its maximum is $0.2 \mathrm{MPa}$.
3.3.2. Selecting Similar Materials for Surrounding Rock and Its Mechanical Parameters. The main prototype materials are grade VI surrounding rock (weathered sandy mudstone) and secondary linings. The test determined relative physicalmechanical parameters of grade VI surrounding rock based on the geological survey and Code for Design of Road Tunnel (JTG D70-20014). Taking the mixture of fine sand, land plaster, bentonite clay, and normal Portland cement 425 as similar materials for surrounding rock, the watercement ratio is $1: 7$. The mechanics index ratios of prototype materials and similar material are shown in Table 5.

3.4. Model Experiment Excavation Steps. This test consisted primarily of research on the excavation method of a shallow, large section tunnel, and it adopted artificial excavation. Its top and bottom pilot headings were excavated from both sides at the same time (Figure 9).

(1) Both sides of the tunnel top- and under-headings would be excavated at the same time.

(2) Excavating core soil and rock beam and digging $10 \mathrm{~cm}$ each time, the excavation space between the top and bottom pilot headings is $10 \mathrm{~cm}$ in each ring.

(3) The cross tunnels were excavated from both sides at the same time by the full-face excavation method.

3.5. Analysis of Experimental Results. The data measurement sensor used in this experiment includes a multipoint displacement meter for measuring displacement, a pressure box for measuring the stress of the surrounding rock, and precision leveling instrument for measuring surface subsidence. The measuring points of the instruments are shown in Figure 10, where $W$ is the span of the tunnel. In order to facilitate subsequent data processing, the measurement points of different parts are numbered (Table 6).

3.5.1. Displacement Analysis of the Surrounding Rock. Layout of measuring points: SWD-b1 to SWD-b4 are multipoint horizontal displacement meters for sidewalls of the main tunnel, HD-b1 to HD-b5 are multipoint displacement meters used to monitor the hance of the main tunnel, and VD-b1 and VD-b2 are multipoint displacement meters for monitoring the displacement of the main tunnel vault. Based on the experiment data, the displacement curves of the measuring points of the main tunnel in the excavation process are obtained, as shown in Figure 11.

As seen in Figure 10, the displacement value of the surrounding rock, which is monitored by multipoint horizontal displacement meter SWD-b1 to SWD-b4 close to the left side of the main tunnel straight wall, is increasing at the second step of the excavation process, and the closer the surrounding rock to the excavation line, the larger the displacement of the surrounding rock. Before the excavation of the secondary tunnel, the displacement values of the horizontal multipoint displacement meter show a negligible change. After the excavation of the secondary tunnel, the displacement of SWD-b1 to SWD-b4, measured by the 
TABLE 3: Lateral displacement of the tunnel.

\begin{tabular}{lccc}
\hline Excavation method & Foot of wall $(\mathrm{mm})$ & Left flank wall $(\mathrm{mm})$ & Left \\
\hline Double-side-wall heading & 6.5 & 13.2 & 9.8 \\
Cross rock beam + heading method & 4.9 & 9.8 & 7.5 \\
\hline
\end{tabular}

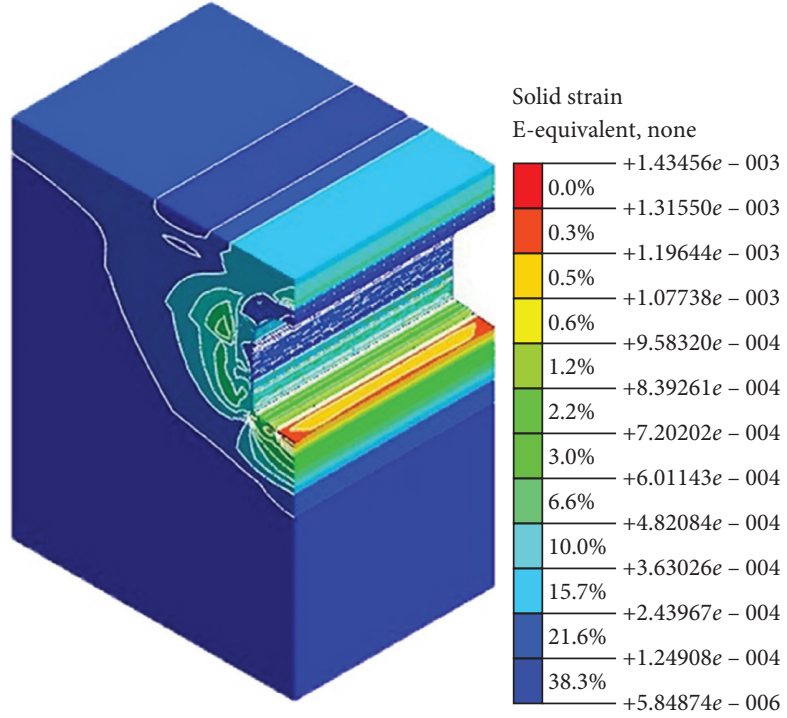

(a)

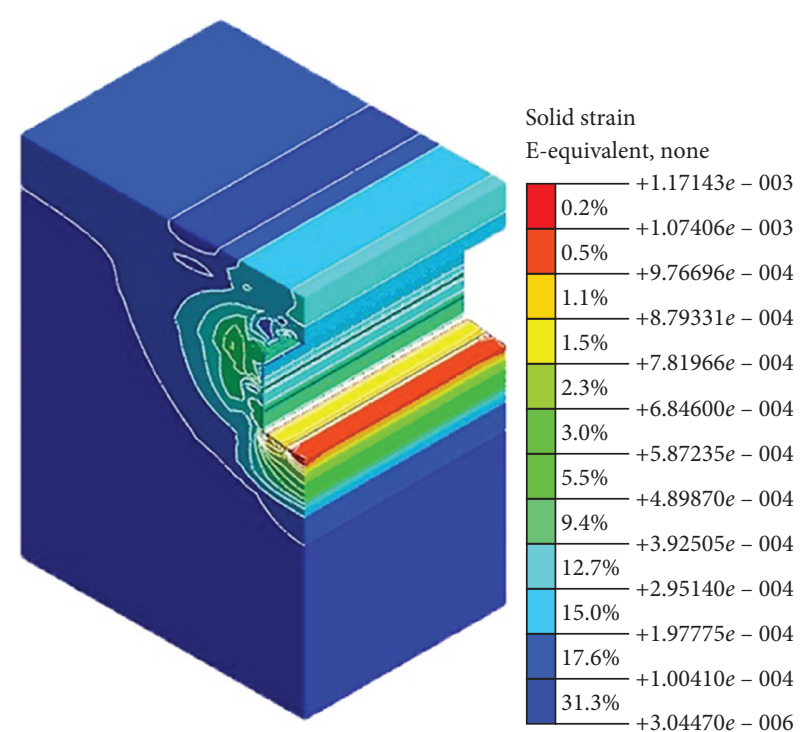

(b)

FIgURE 5: Equivalent plastic strain: (a) double-side-wall heading constructing method; (b) cross rock beam + heading method.

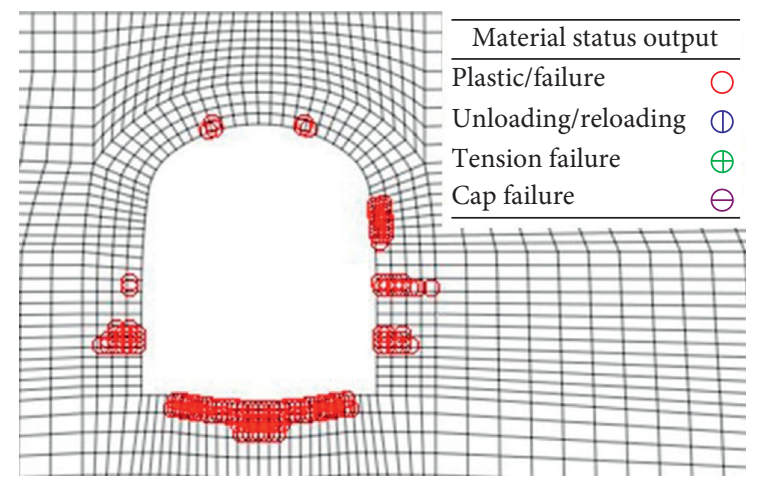

(a)

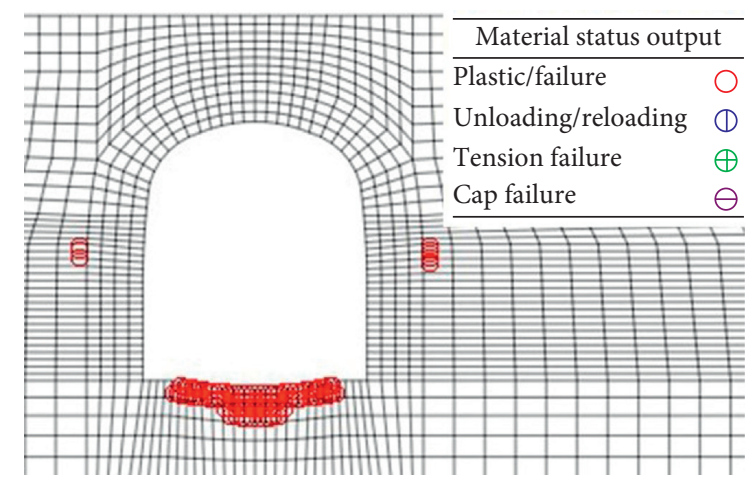

(b)

FIgURE 6: Plastic zone: (a) double-side-wall heading excavation method; (b) cross rock beam + heading method.

Table 4: Principal stress of key points $(\mathrm{kPa})$.

\begin{tabular}{|c|c|c|c|c|c|c|}
\hline Measure point & & Left wall foot & Left flank wall & Left arch foot & Left arch waist & Vault \\
\hline \multirow{2}{*}{ Double-side-wall heading excavation method } & $\sigma_{1}$ & $-1,717.93$ & 544.55 & 194.55 & 279.42 & 758.21 \\
\hline & $\sigma_{3}$ & $-2,670.02$ & $-1,447.14$ & $-1,066.89$ & $-1,060.74$ & -95.19 \\
\hline \multirow{2}{*}{ Cross rock beam + heading method } & $\sigma_{1}$ & $-1,208.40$ & 157.54 & 132.31 & 175.28 & 291.57 \\
\hline & $\sigma_{3}$ & $-1,355.68$ & -527.37 & -755.94 & -354.49 & -375.30 \\
\hline
\end{tabular}

multipoint displacement meter, increased at first, then decreased, and was finally restored to its level before the secondary tunnel excavation (SWD-b4, SWD-b1, and SWD- b3 moved about $0.25 \mathrm{~mm}, 0.78 \mathrm{~mm}$, and $0.54 \mathrm{~mm}$, respectively). During excavation of the main tunnel, the change of the surrounding rock displacement monitored by HD-b1 to 


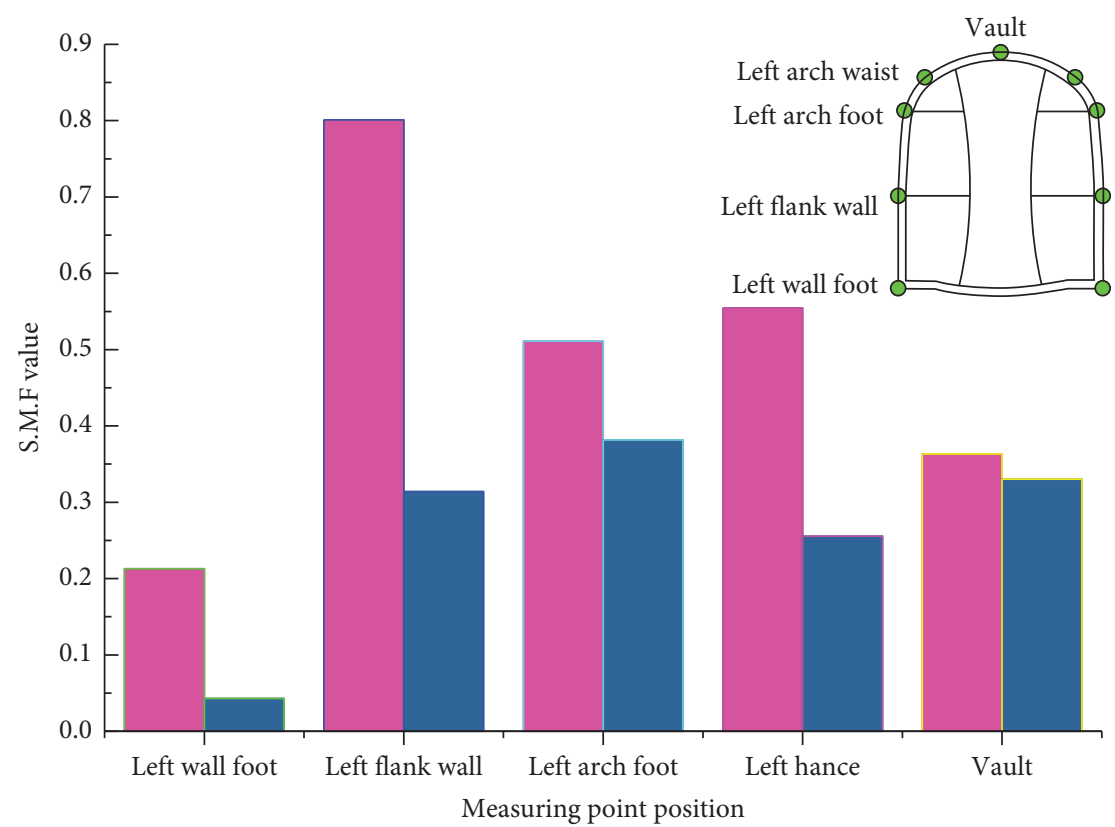

Double-side-wall

Upper and lower side

FIgURE 7: Gauss effective strength coefficient of the key point.

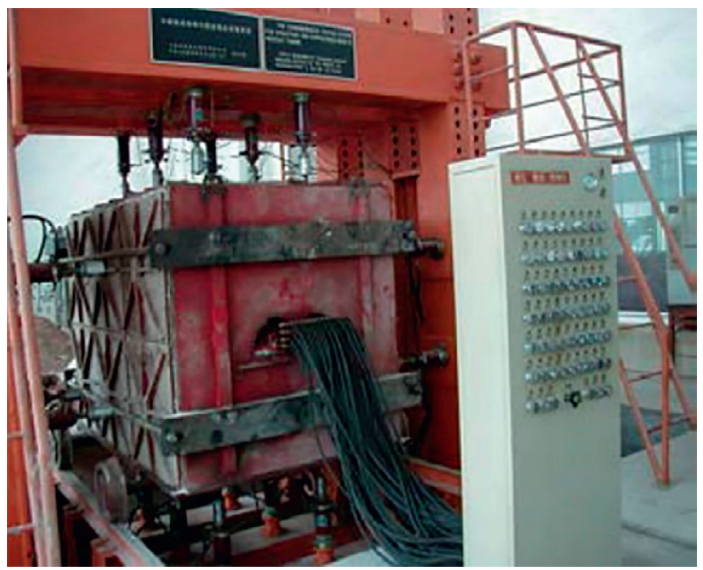

Figure 8: Synthetic experiment system of the tunnel and surrounding rock. Test 1: we cast the surrounding rock proportionately and simulated the cross rock beam + heading method. Test 2: based on the test 1 , we excavated the secondary cross tunnel from the side, adopting the win-side heading method after the excavation and support of the main tunnel.

TABle 5: Principal stress of key points $(\mathrm{kPa})$.

\begin{tabular}{|c|c|c|c|c|c|}
\hline & Geometric size & $E(\mathrm{kPa})$ & $\mu$ & $\gamma\left(\mathrm{kN} \cdot \mathrm{m}^{-3}\right)$ & $\varphi$ \\
\hline Grade VI surrounding rock & 128 & $2.45 \times 10^{6}$ & 0.34 & 25.09 & 34.78 \\
\hline Simulating material & 3.2 & $1.52 \times 10^{5}$ & 0.17 & 19.6 & 35 \\
\hline Proportion & 40 & 16.12 & 2.00 & 1.31 & 0.99 \\
\hline
\end{tabular}

HD-b5 was very small. After excavation of the secondary tunnel, the displacement monitored by HD-b1 to HD-b5 increased and then decreased, and finally, the displacement was consistent with that before the excavation of the branch tunnel. Moreover, the surrounding rock displacement measured by VD-b1 and VD-b2 gradually increased during the excavation of the main and secondary tunnels, but the displacement change was smaller than before with the excavation of the secondary tunnel.

3.5.2. Stress Analysis for the Surrounding Rock. Arrangement of measuring points: SWS-b1 to SWS-b5 are stress meters of the surrounding rock of the main tunnel 


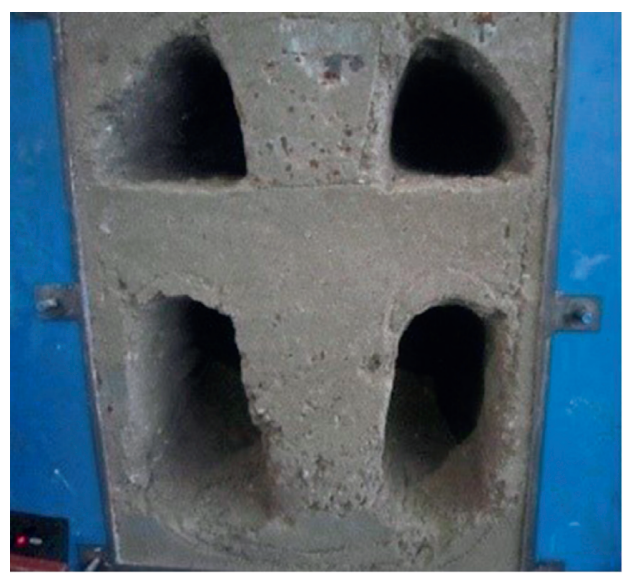

(a)

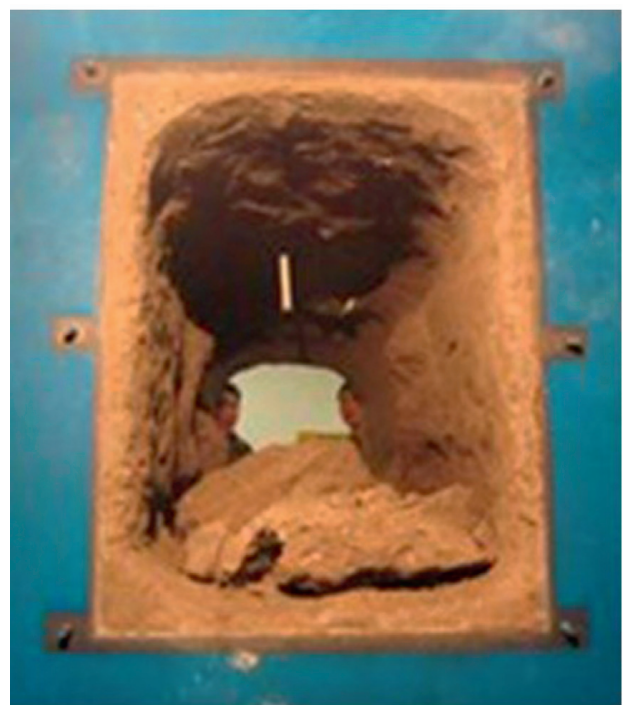

(c)

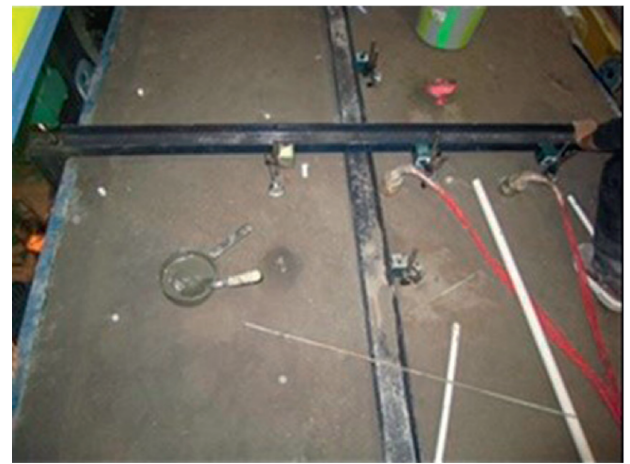

(e)

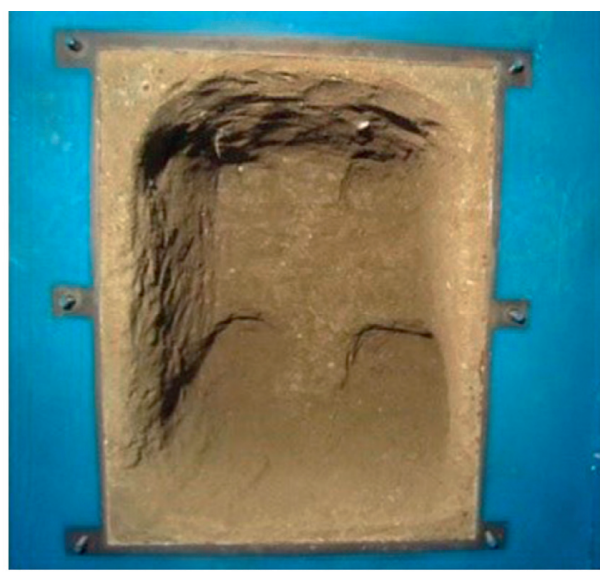

(b)

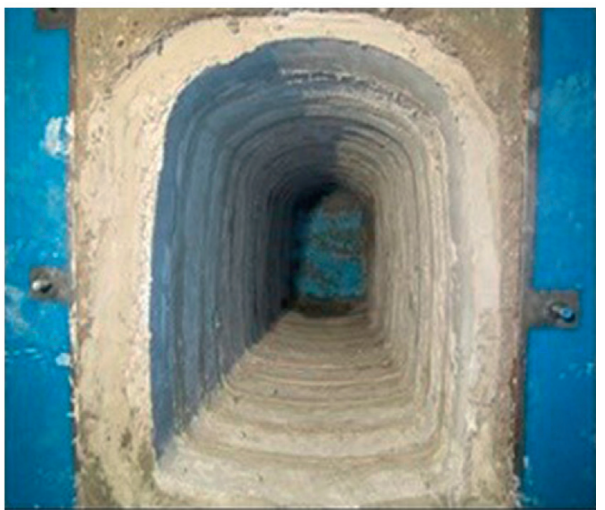

(d)

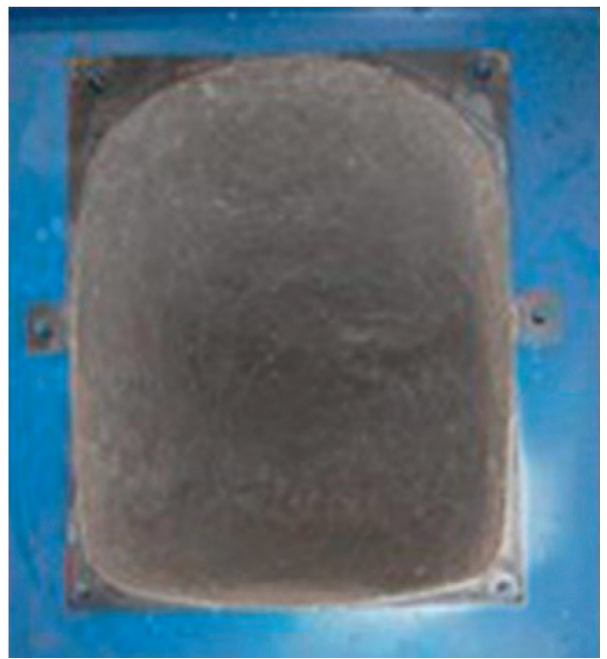

(f)

Figure 9: Model test excavation process: (a) step 1: four pilot headings when excavating the main tunnel for the first time; (b) step 4: excavating core soil and rock beam of the main tunnel for the second time; (c) step 6: excavating core soil and rock beam of the main tunnel for the third time; (d) step 9: secondary lining; (e) step 10: surface injecting; (f) step 14: fourth full-face excavation of the accessorial cross tunnel.

sidewall, HS-b1 to HS-b5 are stress meters of the surrounding rock of the main tunnel hance, and VS-b1 to VSb3 are stress meters of the surrounding rock of the main tunnel vault. IS-b1 to IS-b3 are stress meters of surrounding rock of the main tunnel invert. The stress curves of different measuring points that varied with the excavation process are given by analyzing experiment data, as shown in Figure 12.

Results of the stress test of the surrounding rock and model experiment: 


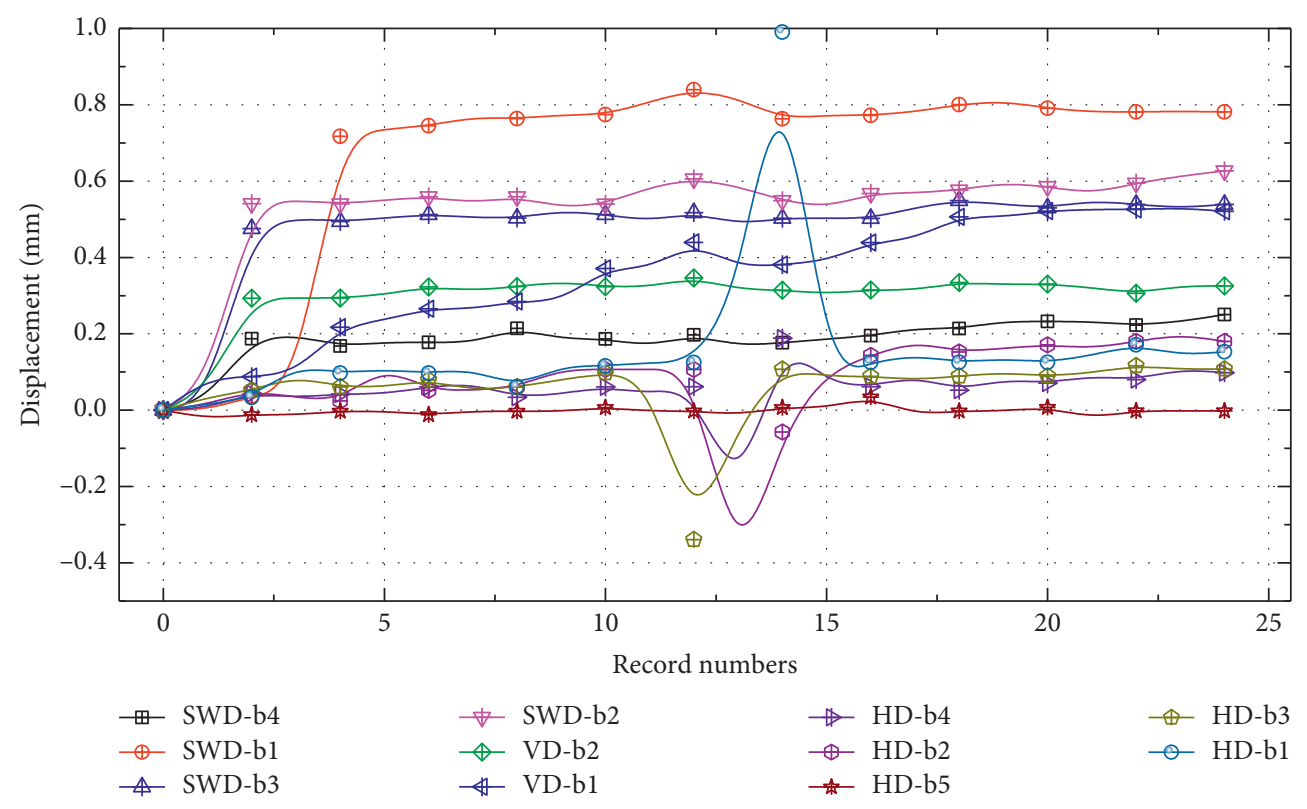

FIgURE 10: Displacement curves of a multipoint displacement meter.

TABle 6: Measuring point codes.

\begin{tabular}{lc}
\hline Code & Note \\
\hline b & b-section \\
H & Hance \\
V & Vault \\
D & Displacement \\
d & d-section \\
SW & Sidewall \\
I & Invert \\
S & Stress \\
\hline
\end{tabular}

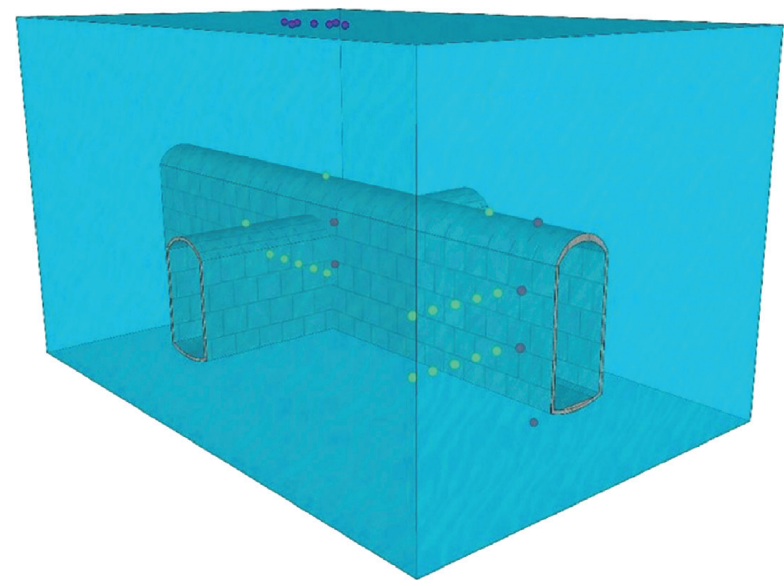

- Dial indicator

- Pressure cell

- Displacement meter

Figure 11: Measuring point layout.

(1) The surrounding rock stress is gradually reduced with the excavation progress of the main tunnel, showing that the tunnel excavation will cause the redistribution of surrounding rock and the stress relief of local layer.

(2) As seen in the model test results, the stress of surrounding rock of the main tunnel increases and tends to be stable after the excavation of the crossed secondary tunnel. The stress of the second lining begins to regain stability, gradually increases after the excavation of the main tunnel, and finally tends to stabilize.

(3) Influenced by the excavated face, the overall shape of the stress-duration curve of the surrounding rock is S-shaped, and the stress changes step-by-step with the excavation. To sum up, the majority of the surrounding rock stress results are normal, which is in accordance with the actual situation.

\subsubsection{Analysis of Surface Subsidence Data.} Measuring-point layout: GD-b1 to GD-b3 are just above the main tunnel ground surface, and measuring points GD-d4 and GD-d5 are on the ground surface directly above the secondary tunnel. According to the data collection and analysis, the curves of different ground surface subsidence with the excavation process are obtained, as shown in Figure 13.

As seen in Figure 13, the settlement of measuring points GD-b1to GD-b3 gradually increases with the excavation progress of the main tunnel, but after the secondary lining structure is applied, the settlement change is smaller than before, with the excavation of the secondary tunnel. When excavating the main tunnel, the settlement of measuring points GD-d4 and GD-d5 is quite small, but it gradually increases with the excavation of the secondary tunnel. Due to the influence of the distance from the tunnel face to the test section, the curves of the surface subsidence are basically 


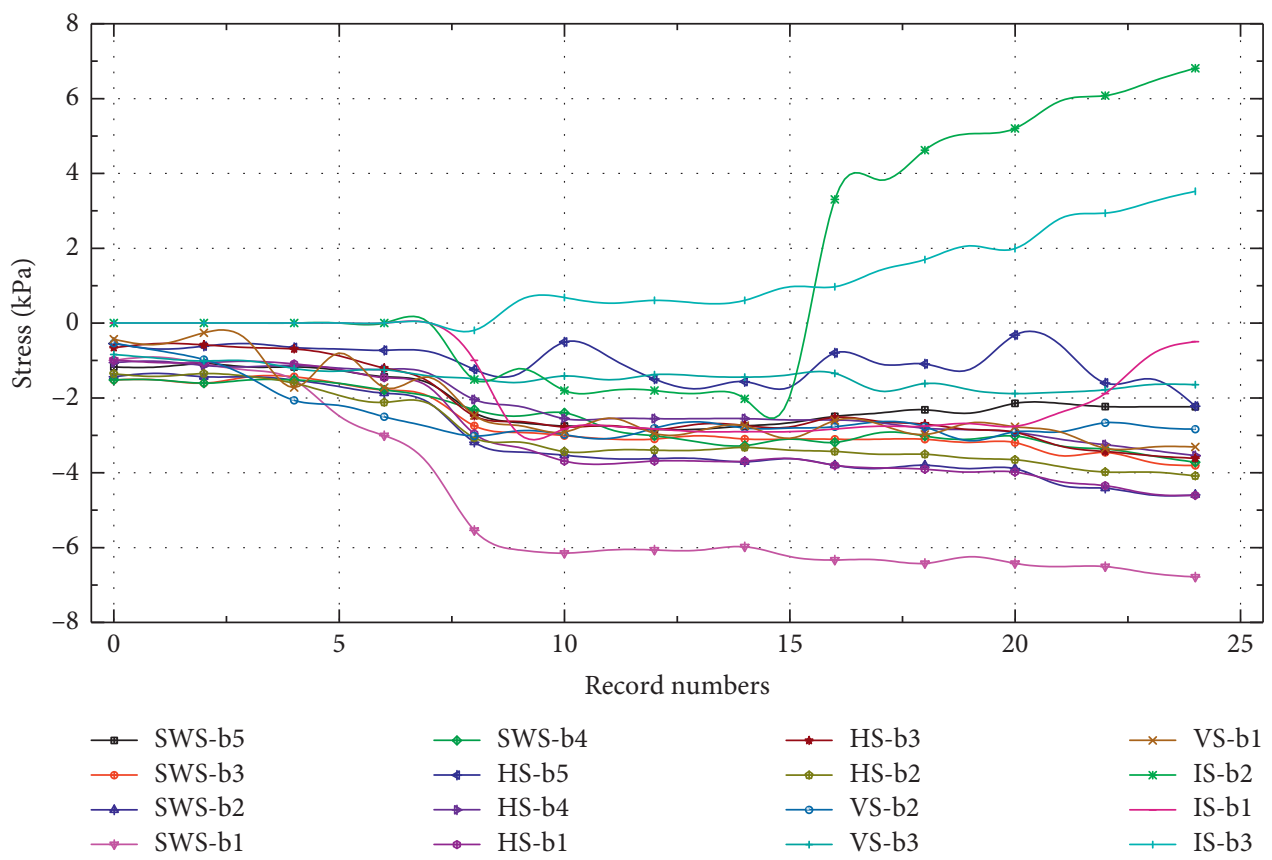

FIgURE 12: Stress-change curves of the surrounding rock and second lining.

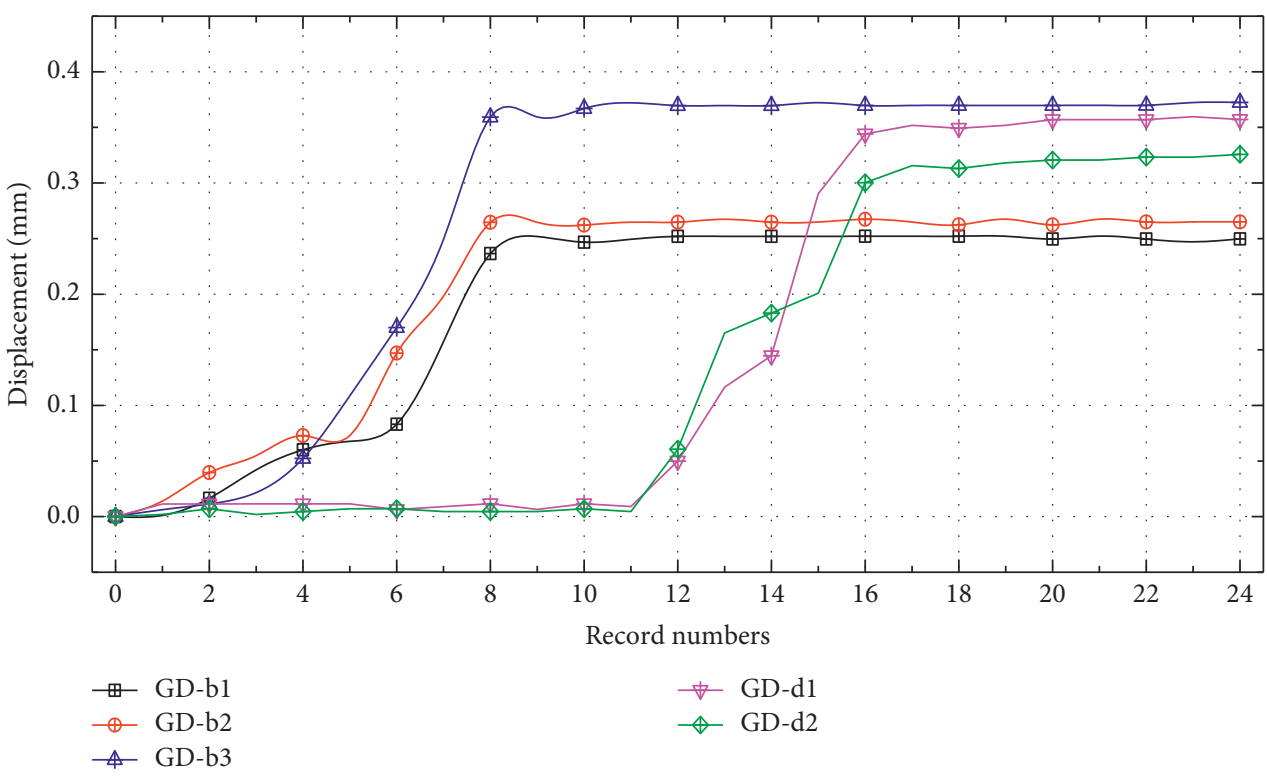

FIGURE 13: Variation curves of surrounding rock and lining stresses with excavation process.

"S" curves, which is consistent with the trend of the tunnel vault sinking.

\section{Conclusion}

We can draw the following conclusions by studying the structure of the large underground transfer metro station, numerical simulation of the tunnel excavation method, and model methods.

(1) This paper proposes a structural form suitable for large-scale metro cross transfer stations and proposes a new construction method for the shallow- buried and concealed excavation of super-large-scale underground structures. Especially, it has wide applicability in the construction of underground excavation of supertall underground structures. At the same time, the construction method of the upperand lower-side heading excavation method solves the safety problem of the design and excavation of the lining trolley.

(2) When the cross section forms of arch-wall intersections are adopted, the stage construction of the tunnel with cross section types B and D is carried out. Under such conditions, the B-type section plays the 
main load-bearing role, which can significantly reduce the excavation area. In addition, the arch structure of the tunnel excavation section is more reasonable and explicit, and the overall project risk is easy to control.

(3) At the intersection, the underground rock formations of the tunnel arch are microweathered sandstone and mudstone, and the integrity of the rock mass is good, with no development of joint fissures. In the form of the arch-wall intersecting structure, the rock formation in the elevated position of the tunnel arch is mainly mudstone, so that the bearing capacity of the sandstone is not weakened, the excavation has little effect on the stability of the surrounding rock, and the overall condition is favorable for the self-stabilization of the tunnel cavity.

(4) For the large section shallow-buried station, when adopting the cross rock beam + heading method, the stability of the surrounding rock and the mechanical performance of the supporting structure are superior to the double-side-wall heading excavation method.

(5) The main tunnel is dug by the cross rock beam + heading method, the excavation of the cross rock beam + heading method has a great influence on the displacement of the tunnel vault, and the excavation of the core soil steps causes the maximum subsidence of the surface. Therefore, these are key steps to control surface subsidence and tunnelstructure stability and safety. In the main tunnel excavation process, both side corners of the wall are in a state of compression at all times, and large surrounding rock stress can be found at the wall waist, arch foot, arch waist, and tunnel vault, mainly due to compressive stress.

(6) It is advised to adopt full-face excavation for the crossing secondary tunnel. This has a great influence upon displacement around the surrounding rock, and the settlement of the tunnel vault is the largest, but the surrounding rock displacement of the main tunnel is almost unchanged. The stress, characterized by compressive stress around the main tunnel, gradually increases with the excavation of the crossing secondary tunnel, and the absolute value of the compressive stress on the hance and arch foot is the largest. The inverted arch stress of the second lining changes from compression stress to tensile stress with excavation progress, and the compression stress value is larger.

\section{Data Availability}

The data used to support the findings of this study are included within the article.

\section{Conflicts of Interest}

The authors declare that they have no conflicts of interest.

\section{Acknowledgments}

The authors gratefully acknowledge funding by the National Natural Science Foundation Project of China (51904043), the Project of the Scientific and Technological Research Program of Chongqing Municipal Education Commission (KJQN201901240), and Chongqing Engineering Research Center of Disaster Prevention and Control for Banks and Structures in Three Gorges Reservoir Area (SAXPGC18ZDI04P).

\section{References}

[1] N.-H. Liang, X.-R. Liu, X.-S. Cao, Z.-J. Zhong, and J. Liao, "Present situation and developing strategy of urban subway construction in P. R. China," Journal of Civil, Architectural \& Environmental Engineering, vol. 30, no. 6, pp. 81-85, 2008.

[2] H. Xie, J. W. Zhao, H. W. Zhou, S. H. Ren, and R. X. Zhang, "Secondary utilizations and perspectives of mined underground space," Tunnelling and Underground Space Technology, vol. 96, Article ID 103129, 2020.

[3] H. Lei, S. Yu, and W. Xuan, "Investigation on urban design with integration of above-and under-ground space around subway station," Chinese Journal of Underground Space and Engineering, vol. 2, no. 7, pp. 1199-1203, 2006.

[4] W. Broere, "Urban underground space: solving the problems of today's cities," Tunnelling and Underground Space Technology, vol. 55, pp. 245-248, 2016.

[5] L. Chen, G.-X. Chen, and H. Long, "3D refined nonlinear finite element analysis of intersecting metro tunnels under near-field ground motion," Rock and Soil Mechanics, vol. 12, pp. 280-285, 2010.

[6] L. Daming, S. Yanjun, and L. Kan, "Stress and displacement analysis of surround rock in y-shape tunnel," Chinese Journal of Underground Space \& Engineering, vol. 8, no. 6, pp. 1153-1158, 2012.

[7] C.-J. Xu, Y.-L. Wang, Y.-L. Xu, and J.-C. Wang, "Effect of foundation pit excavation and structural construction of new engineering on existing underlying tunnel," Rock and Soil Mechanics, vol. 36, no. 11, pp. 3201-3209, 2015.

[8] Q. Jiang, G. Su, X.-t. Feng, G. Chen, M.-z. Zhang, and C. Liu, "Excavation optimization and stability analysis for large underground caverns under high geostress: a case study of the Chinese laxiwa project," Rock Mechanics and Rock Engineering, vol. 52, no. 3, pp. 895-915, 2019.

[9] D. Zhou, L. Cao, Y. Ma, S. Fang, and K. Wang, "Research on construction behaviors of support system in four-lane ultra large-span tunnel with super-large cross-section," Chinese Journal of Rock Mechanics and Engineering, vol. 29, no. 1, pp. 140-148, 2010.

[10] Q. Jiang, B. Yang, F. Yan, C. Liu, Y. Shi, and L. Li, "New method for characterizing the shear damage of natural rock joint based on 3d engraving and 3d scanning," International Journal of Geomechanics, vol. 20, no. 2, Article ID 06019022, 2020.

[11] A. V. Kivi, M. H. Sadaghiani, and M. M. Ahmadi, "Numerical modeling of ground settlement control of large span underground metro station in tehran metro using central beam column (CBC) structure," Tunnelling and Underground Space Technology, vol. 28, pp. 1-9, 2012.

[12] M. Devriendt, "Risk analysis for tunnelling ground movement assessments," Proceedings of the Institution of Civil EngineersGeotechnical Engineering, vol. 163, no. 3, pp. 109-118, 2010. 
[13] R. Farrell, R. Mair, A. Sciotti, and A. Pigorini, "Building response to tunnelling," Soils and Foundations, vol. 54, no. 3, pp. 269-279, 2014.

[14] B. Li and Z. Z. Wang, "Numerical study on the response of ground movements to construction activities of a metro station using the pile-beam-arch method," Tunnelling and Underground Space Technology, vol. 88, pp. 209-220, 2019.

[15] C. Y. Heng, S. Sun, Z. Zhou, and J. T. Zhang, "Prediction of surface settlement with ultra-shallow-burial and large rectangular cross-section urban underpass," KSCE Journal of Civil Engineering, vol. 23, no. 11, pp. 4641-4650, 2019.

[16] D. Zhang, P. Li, Y. Hou, and J. Luo, "Experimental study on safety control of buildings during construction of shallowburied soft rock tunnel with large-section," Chinese Journal of Rock Mechanics and Engineering, vol. 1, pp. 95-102, 2009.

[17] C. Liu, S. Li, Z. Zhou, L. Li, K. Wang, and C. Qin, "Model test study on spatial deformation law of surrounding rock for super-large section and shallow buried tunnels," Geotechnical Testing Journal, vol. 42, no. 3, Article ID 20170243, 724 pages, 2019.

[18] M. H. Sadaghiani and S. Dadizadeh, "Study on the effect of a new construction method for a large span metro underground station in tabriz-iran," Tunnelling and Underground Space Technology, vol. 25, no. 1, pp. 63-69, 2010.

[19] Y.-F. Chen, H.-K. Zheng, M. Wang, J.-M. Hong, and C.-B. Zhou, "Excavation-induced relaxation effects and hydraulic conductivity variations in the surrounding rocks of a large-scale underground powerhouse cavern system," Tunnelling and Underground Space Technology, vol. 49, pp. 253267, 2015.

[20] X. W. Wang, J. T. Chen, and M. Xiao, "Seismic damage assessment and mechanism analysis of underground powerhouse of the yingxiuwan hydropower station under the wenchuan earthquake," Soil Dynamics and Earthquake Engineering, vol. 113, pp. 112-123, 2018.

[21] S. L. Chen, S. C. Lee, and M. W. Gui, "Effects of rock pillar width on the excavation behavior of parallel tunnels," Tunnelling and Underground Space Technology, vol. 24, no. 2, pp. 148-154, 2009.

[22] I. Yamaguchi, I. Yamazaki, and Y. Kiritani, "Study of groundtunnel interactions of four shield tunnels driven in close proximity, in relation to design and construction of parallel shield tunnels," Tunnelling and Underground Space Technology, vol. 13, no. 3, pp. 289-304, 1998.

[23] Qiu W., Zheng Y., Hu H., Study on Zoning of Adjacent Influence on Shallow Embedded and Overlap Metro Tunnels Constructed by Conventional Method.

[24] X. G. Li and D. J. Yuan, "Response of a double-decked metro tunnel to shield driving of twin closely under-crossing tunnels," Tunnelling and Underground Space Technology, vol. 28, pp. 18-30, 2012.

[25] W. S. Zhu, S. C. Li, and W. Z. Chen, Failure Mechanism and Anchoring Effect of Jointed Rock Mass and Its Engineering Application, Science Press, Beijing, China, 2002. 